\title{
Health promotion: Criticism of everyday life medicalization practices
}

\author{
Kênia Silva, Roseni Sena \\ School of Nursing, National University of Minas Gerais, Brasil \\ Correspondence: Kênia Silva. 131 Furtado Nunes st, 101, Belo Horizonte, CEP 30730090, Minas Gerais, Brasil. \\ Telephone: 55-31-3409-9181. Email: kenialara17@yahoo.com.br.
}

Received: October 19, 2012

Accepted: December 26, 2012

Online Published: March 6, 2013

DOI : $10.5430 /$ jnep.v3n9p83

URL: http://dx.doi.org/10.5430/jnep.v3n9p83

\begin{abstract}
The aim of this study was to analyze the meanings of the practices of health promotion. The results indicate that the practices in different social areas are sustained within the mechanisms of social control and management of vulnerable populations. Thus, there is the feedback of the biomedical paradigm now materialized in different practices in different areas beyond the traditional health services. It is concluded that health promotion in areas of daily life presents the challenge of expanding the potential autonomy of action of individuals in movements that consider the potential social areas in constant transformation of everyday life.
\end{abstract}

\section{Key words}

Health promotion, Community health promotion, Community health psychology, Critical health psychology, Qualitative methods

\section{I ntroduction}

The work is the result of research which used as a subject the promotion of health practices in areas of everyday life.

Health promotion policy-making exhibits a strong ideological hue. Releases on the subject in Brazil were constructed aggregating concepts and technologies that are expressed in projects that reflect different conceptions of the healthdisease ${ }^{[1,2]}$. In the last three decades of the twentieth century, the concept of health promotion has developed vigorously in the country and had its conceptual basis and policies discussed in international events like the International Conferences on Health Promotion in Brazil and that reverberated in the formulation of a National Policies for Health Promotion.

In this study, we adopted the category of the social area as a field for the study of health promotion by understanding that health is generated in all areas where people live, love, work and entertain themselves by referring, as the "place" as an organized space for analysis and intervention. There is a potential for health development in virtually every organization or community. This understanding allows taking over social spaces as demonstrators of the meanings of health promotion that are assumed within.

Areas for health promotion can be defined as the place or social context in which people in their daily activities, interact with environmental factors, social and personal that affect health and well-being ${ }^{[3,4]}$. Thus, the areas are the locations 
established by social actors, a product of a social dynamic, where the subjects form a strong bond in the struggle for their interest in objective and subjective necessity. Within its boundaries, the subjects reflect a certain model of intervention, at reflecting rules, conventions and schemes related to health promotion.

Health promotion is presented in a variety of complex initiatives in its aims, content and implementation strategies ${ }^{[3]}$ that highlight the collective nature of health promotion actions that reflect the extent to which organizational factors are potent in determining the behaviour of individuals and groups, as they can be adjusted to each specific context. The analysis of these areas reveals the disciplinary power operating constantly and across, the individual and collective bodies. This understanding is essential to anchor changes in health practices whereas beyond institutional speeches, regulatory health promotion reveals how power relations become rooted in social networks having daily life as a place where the disciplinary power circulates, producing domesticated, docile bodies ${ }^{[5-7]}$.

The analysis of health promotion practices, supports the assumption that the purpose of surveillance and the notion of risk that prescribes the conducts, habits and lifestyles considered "healthy" in the strategies and actions to promote health, are expressed as power techniques reinforcing a disciplinary society, standardized and regulated ${ }^{[5-7]}$.

Thus, depending on the way they are structured, promotion actions can become surveillance strategies that often limit or restrict the freedoms and individual decisions, with the motivation of collective well-being or the avoidability of harmful consequences to health and society, in a discourse of life medicalization. The strategies in the field of health promotion could be limiting the autonomy and freedom when held in practice aimed at habits and lifestyle modifications that do not contribute to subjects exercising their choices in building their projects and ways of life, including their demands, needs and health expectations.

Thus the objective of this study was to analyze the way of life in social areas of everyday life revealing the direction and meanings of health promotion. Specifically, this work shows the analysis of health promotion practices learned in social areas of everyday life on the scenario of the study: the school and the fitness group Unibiótica.

\section{Methodology}

It is a qualitative research approach supported in the framework of the Sociology of Everyday Life ${ }^{[8,9]}$ in the field of knowledge that enabled the understanding of everyday life and its relations with the macro and microstructures of society. From this perspective it is understood that the freedom and autonomy in the everyday world are possibilities of the subject to interpret the content of social norms, rejecting some, accepting others, or even preferring other values, because everyday life is full of choices and alternatives ${ }^{[8]}$. Thus, it is possible to reveal the structure of a given society by examining the life and habitual thoughts.

The analysis of the everyday routines was taken in 2010 at St. Joseph's neighbourhod, the location of the Municipal Health Department of Belo Horizonte, Brazil. In this location reside about 4,500 families, around 18,900 people. It contains an area of town that at the time of the study was undergoing resettlement, where the houses and sheds will be removed and will give rise to an extension of an avenue.

The spaces analyzed in the health promotion study were: two Schools, the Recreation Club, the avenue where the walking activity takes place, and the Unibiotica Fitness group. In these spaces, we could identify several practices that contribute to the increase of the population's health and, as a result, can be understood as practices of health promotion. However health promotion constitutes an institutional field that claims for itself a more or less specific set of actions grounded in theoretical and methodological references that ensure its sustainability. Thus, in view of the entirety of identified practices in the areas, was selected for in-depth analysis, those who approach a categorical matrix that makes up the promotion of health and contributes to the development of theoretical and practical field. 
The construction of the empirical data resulted from observations, 33 interviews and conversations in the defined area of study. The field journal was an essential tool in reporting the observation of the practices in the different spaces. In it, all moments experienced in capturing the reality were carefully reproduced; the characteristics, interactions and individual aspects were registered as well as the researcher's feelings in the experienced practices and their interpretation. The recordings compose the framework of the social representations, i.e. the categories of thought, action and feeling that express the reality and that try to explain it, question it and justify it ${ }^{[10]}$.

In presenting the results, data from the experience in these areas are listed as observation notes, followed by the date in which the experience took place. The analysis was carried out via the Hermeneutic-Dialectic method that grasps the individuals social experience in their contradictory movement and considers the realities and contingent on history allowing the simultaneous existence of "(...) collective interests that unite and interests that distinguish and contrast" ${ }^{[11]}$.

\section{Health promotion in the area of everyday life}

The systematic mapping of the scenario study revealed the existence of different social spaces that are important to promote the population's life and health quality. When I speak of social spaces, I refer to equipment and social movements that shape the daily life in the territory. The location recording and equipment movements reveal disparities in the availability and distribution of resources. The mapping analysis shows areas of high and low social spaces deprivation in the territory. The study findings support the view that the urban structure expresses the cities' inequalities of access to materialized resources in urban areas, due to the residential location and the uneven distribution of facilities, urban services, income and social benefits. On the use of the public spaces, that certain sectors of the population tend to develop their own ways of interacting with the space, regardless of the uses officially expected, which somehow represents a practical and symbolic subversion that resonates in the everyday uses of city spaces. With that in mind, we could reflect on the underutilization of existing spaces in this scenario: there is no activity in the soccer pitch during the week, only championships on Saturdays. In the squares, the flow of people is restricted to those who use them as a route for going to work and for everyday activities like shopping. In the club, movement is intense only on sunny weekends.

These findings seem important since there is a link between the spaces location and the practice of physical exercise that even adopting a behaviourist approach to health promotion can not be disregarded as an incentive to a healthy practice. The large quantity of facilities for the practice of physical exercise, besides serving as a visual stimulus, calling people's attention to it, reduces the physical and psychological barriers associated with workout, since the proximity to the place of exercise decreases the time people need to arrive at it ${ }^{[12]}$. We must consider also that the outdoor spaces contribute to an active life and represent a significant part of a community identity. Therefore Ferreira and Najar ${ }^{[12]}$ suggest that environmental interventions, as a public policy element, can influence population groups. Furthermore, the analysis of the geographical content of the quotidian contributes to the understanding of the relationship between space and social movements, considering the materiality, as a condition for action, a control structure, a limit to the action, a call to action. The practices of health promotion have been revealed in people's daily life in many social spaces. Some, as the walking activity, have proved to be recognised by the population as an experience "to be healthy". Others like the Unibiotica Fitness Classes have been introduced by the health professionals. Others still have been revealed when some spaces have been proposed for analysis, like the practices in schools

\section{1) The School as a place for health promotion}

The inclusion of the school as a place for the analysis of health promotion was due to the fact of understanding it as a place for (re)production of health promotion practices. Recent studies have shown its potential to instil in students new habits and healthy lifestyles ${ }^{[13]}$. Parcel et al ${ }^{[14]}$ highlight how much the school represents a potential place for the development of health promotion: the majority of children spend much of their time in school (at least one turn, or those proposed for full-time comprehensive school, round and counter-turn), the different activities that children and adolescents develop in 
school-learning, entertainment, food and socializing - creates a diverse field of behavioural control, where they can learn, practice and reinforce healthy choices.

Traditionally, the school is taken as a space for reproduction of supra-state structure to engender relationships and practices that are emerging in everyday school life, the concrete situations of order, discipline and hierarchy that structure social relations. The function of the school and other institutions, are not to repress or shape people in their roles of control, but to exert supervision upon the standards of their members; in their repressive role they exert punishment over institutional deviants ${ }^{[15]}$.

The study findings indicate that, with the school, the concepts of health promotion on the current hegemonic society are focused on modification of lifestyle habits and individual behaviour. Outstanding health promotion actions are indicated by the social actors in schools, physical education activities (which focuses on the individual) and investing in healthy eating. There is also the association of health promotion with health education (especially sexual education) and disease prevention, which includes adolescent pregnancy. In some speeches, it is possible to grasp the movement of the school in order to incorporate discussions referring to the expanded field of health related to the rights of citizenship and the environment. The intersectorial action is presented as a necessity to correspond to the demands of health (or disease) that are revealed in this area.

The findings point to an understanding where the school area is a reproduction of disciplinary power, reinforcing the traditional focus on health hazards and the causes of disease and therefore the extent of space and exercise biomedical normativity of social medicalization. Veiga ${ }^{[15]}$ corroborates this argument by stating that the monopolization of knowledge by the State and the universalization of education is extended to the entire population models of auto-coercion, the domain of emotions, the senses of shame and embarrassment, spreading another configuration of society by inventing an educated class as a social activity category.

On the other hand, the analysis of the data allowed an understanding that the school is also a place for creation of a new modus vivendi, and therefore a space that reveals autonomy in the way of living. This potential is revealed, for example, during an observed conversation between employees of a municipal school, when preparing snacks, they discuss the Director's determination not to offer fizzy drinks to "not get the boys used to it..." The "not get used to it" is presumed to be a break with the established patterns of consumption in society, even though it originated from a normalization. This reiterates the argument that the existing power relations and the means of circulation of power can not be only negative but also creative and are presented in a heterogeneous and constant transformation. Therefore, it is not a unitary and totalizing category, on the contrary, is diffusive and it manifests itself in the relationship between forces that weave a complex web of micro-and macro-powers ${ }^{[6]}$.

The practices examined in the areas of schools was the walk against dengue, held as an activity of health education at the school borough and the full time school project of a state school. The first practice stood out as an activity that mobilized the whole school (and the entire borough) of an impending dengue epidemic in the borough. The whole society was mobilized to create strategies to promote the prevention of the disease. In the context of the school, teachers were asked to address the theme through various activities: lectures, creating wall displays and educative demonstrations, including the walk against dengue.

The social actors involved were teachers, students, school staff and two Military Police soldiers mobilized to contain the car traffic during the march. All students of all grades should have had participated. This involved a mobilization and teachers should have had required works related to the topic. The school wall display was full of posters about dengue. However, not all of the actors participated with the same motivation. You could see apathy in the students. Many were there for compulsory reasons only and many used the opportunity just to flirt, pull, so not becoming involved in the objective. It reveals the direction of exerting power as a strategy in addressing standardization. 
Although the concept of the walk against dengue should have been potent in promoting social inclusion and intersectioral articulation, this has not happened. It was an isolated movement of the school that did not aggregate the population nor other sectors. The local health service, which is a few meters from the school, did not know about the event.

The analysis revealed the conformation of the practice of constant surveillance technology which is evoked in the population: "Watch yours and your neighbour's house to avoid leaving standing water" (conversations between students). It is evident that the disciplinary role of the school in reproducing the eyes of the State, functioning as a device of social regulation. At the same time, the analysis of the practice raises the discussion on restricting freedoms on leading life. This discussion is anchored in the ground that, the practices of health in different social areas, is to convene a people's autonomy, this autonomy is regulated by ways of everyday life, in which the boundary between public and private limits the construction of citizen's rights.

The other practice analysis was the full-time comprehensive school, revealed as a practice of health promotion in a state school through providing access to large stocks of food, hygiene and physical activities. The fact that the comprehensive school is aimed at a restricted group of students, especially those with learning difficulties or those who are at a social risk (families with alcohol or drugs, domestic violence and sexual abuse) puts this practice as a device for the classification of the subjects, once there is a differentiation of one group of students from the others. At the same time sets limits are established which defines the special needs "student". As such, it is a device for the functioning of power relations.

The findings indicate the need to also examine the comprehensive school as a practice that has a component eugenicisthygienist aimed at the control and discipline of the student's 'problems' in order to correct deviation of behaviour

On the other hand, the data allow us to consider the component present in the emancipation of comprehensive school as a possibility of access to goods (culture, sports and leisure) and coping with social difficulties and thus the creation of new habits. In fact, the proposal of the full-time comprehensive school is actually to promote integration through sports activities and extra support with tutoring from the school as the backbone to confronting social issues.

Gathered empirical data, revealed the full-time comprehensive school as an isolated case of the educational sector and in the study setting, do not conclude an intersectorial articulation in its development. Supervisors of the activities conducted on the counter-part are hired by the Education Department and divide the potential that this practice could have in producing assertive, flexible and combined answers, in a citizen's right and right of sustainable development of the area, at materializing an synergistic public action to ensure effectiveness and social equity in its results, as public sector policy does not produce effective results on its own ${ }^{[16]}$.

The data analysed at the full-time comprehensive school reiterates the focal nature of health promotion actions in the territory, such as access to comprehensive school is not universal, but directed at the group of students with 'problems', turns out to be a classification device and reproduction of those considered outside of the normal range. Contribute to this reflection, the indications of Valla ${ }^{[17]}$ on the trend of application of compensatory policies that do not show intentionality of inclusion, but are protagnators of exclusion.

The results indicate that the school area plays the role of reproducing power relations in society that extends to the field of health promotion. There is a strong indication that this space, according to its characteristic of the state apparatus, contributes as a mechanism of regulation and social cohesion. Another element that should be highlighted in the analysis of the school as a place for health promotion is its dual role of reproduction. At the same time, the accessibility features even in vulnerable areas like the scenario of study are the fulfilment of constitutionality to have all the children in school and capillarity - family involvement, or at least to have them taking part in school activities - the school makes an extensive circulation of disciplinary discourses, the school also reflects the dominant conception of health in society. Thus, when viewing the wall displays "sport and health" and "dengue is a problem for all of us". "Everyone must do their part to avoid "(observation notes) and at the hearing, the majority of students and their mothers and brothers, helped us in the task, what is understood is an organization of speech, present in students, families and everyday community life. 
The results show the potential of school as a place to build emancipator ways of life, from viable and attractive options for actions for promoting health in everyday life. This capability is recognized to the extent that the people who live within access of the codes important for citizenship and social life and, therefore, build a new modus vivendi. Thus, the findings reiterate the Valadão ${ }^{[18]}$, revealing that the components that make the school a key place for health promotion are the fact that the health scenario, where it is expressed, is a determined and produced area; where health education is a curriculum component and can be taken as a cooperative work place and a complimentary health care system.

Data analysis indicates the need for the school to move ahead with overcoming intersectoral endogenous action, limited at the curriculum and "take the opportunity" with the possibilities of intersectoral coordination that arise in everyday life. The walk against dengue represented one of these possibilities. Also with regard to the component of social integration, there are several possibilities identified in school life, especially with the practice at the full-time comprehensive school which is in need of further clarification in order to address the vulnerabilities in the area. The vulnerability in this space is widely taken as a generator of demand and not as a subsidy for the construction of emancipator practices and accountability.

\section{2) Walking and sports activities and recreation: the body of evidence}

Encouraging physical activity is one of the main structures of health promotion in everyday life ${ }^{[19]}$.

In the field of study, it was observed that around 30 people go street walking every day, usually senior women, living in areas of low vulnerability. People either walk alone or in company. Guided street walking groups have not been identified, therefore this attributes a feature of independence and a non-institutional practice.

In the population reports, the street walk appears as a practice overvalued in relation to health promotion, revealing a standardization device, meaning that street walking is what is normally expected in terms of standard exercise. At the same time street walking represents another mechanism of individual self discipline in maintaining a healthy level of fitness, by keeping track of the amount of exercise (monitoring duration of time and repetition).

Another important area of physical activity in the study setting was a leisure club that offered swimming lessons and water aerobics and maintained a partnership with the local government for a socialization project with youths and children.

The people who attended the leisure club during this study were living in areas of low vulnerability. The socialization project with youths and children can be taken as an example of a practice that offers complementary activities to children and adolescents in situations of poverty and social vulnerability: allowing access to leisure, sports and culture. Good school performance is a condition for the inclusion of boys and continuity in the project that happens on the counter-part of the school in an attempt to enable children and adolescents to socialize.

However, the experience in this area has highlighted that there is an erosion of potential emancipation of the practice revealed by the sustained expression of the disciplinary power of norms and rules that reproduce the school models with devices such as call lists, lunch queues, etc. One must also consider what is characterized as a focal practice.

The analysis of the practices of street walking, sports and recreational activities reveals the potential for independence and non-institutionalization. This feature seems essential for the establishment of autonomy. However, it is observed that the two practices are restricted to a small portion of the population with characteristics and social and economic conditions that do not represent the majority. Even in the area of street walking, where access is free and open, the majority of the high vulnerability population are not present. This finding supports the analysis of the need to build strategies that increase people's ability to create accessible and affordable options for physical activity, giving them the responsibility of assuming new habits that contribute to health. The guided street walking groups may represent an alternative to that effect.

The practices also revealed a pattern of the movement of power within society that has the information, advertising, media and medical discourse as the centre of evoking knowledge, therefore the distribution of power. This power focuses and 
highlights the individuals' physiques as an object to be disciplined under determined rules and standards which are to be followed.

In this movement, the technologies of the self are powerful devices for exercising power, revealing itself mainly in the expression "(...) the body as the main target of concern. Working like an identity mark and tending to express the unique self, as if it were exclusive and without any connection with the social field" ${ }^{[20]}$.

It is noteworthy too, in these areas, the predominance of the female public confirming the convergence of the discourses of health and beauty, representing a form of desire for control over one's own body in search of building a healthy body, representing control and discipline, reported by Castro ${ }^{[21]}$.

Thus, the contradiction is expressed: in the practices where more autonomy/freedom were expected, what was revealed was the increased incision of disciplinary power working across individual bodies in the process of constant medicalization.

\section{3) Unibiótica Group}

The Unibiótica was revealed as a practice of health promotion by health professionals, religious representatives, in the interviews and observation of everyday life amongst the population, I identified a church hall as a place where women gather to practice physical activity. They are organized into two groups that meet twice a week in the Church Hall (group 1) and Leisure Club (group 2). It is a non-institutionalized practice, but not completely autonomous once it follows the general guidelines formulated by the Unibiótica’s Korean doctor Jonk Suk Yum.

The method of Unibiótica is the approach of "natural recovery and preservation of health, which summarizes itself with all the scientific knowledge that obeys the Laws of Nature." (notes of analysis, UNIBIÓTICA guidelines ). The Group is led by a senior female resident who resides in an area where there is a program which involves health, physical exercise, nutritional advice and therapeutic baths. The group is called "Holding Hands" (1 and 2) and follows the general guidelines of Unibiótica whose motto is 'Improving All, Improving Everyone'. The support of exercises performed and the dietary advice and attitudes based on studies of the Korean Doctor Jonk Suk Yum on a proposal that unite alternative medicine, physiotherapy, exercises and fitness aimed at maintaining a strong immune system (notes of analysis, UNIBIÒTICA Guidelines).

It stands out in the Unibiótica guidlines that the elements necessary to strengthen the T lymphocyte, natural life (healthy habits, the morning sun, clean air, pure water, natural diet), positive attitudes (honesty, loyalty, friendship, love, charity, joy, forgiveness), moderation (having control, not exaggerating, especially with food), exercise (walking, swimming, cycling, and the easy exercises designed by Unibiótica which are accessible to anyone).

Participation in the Unibiótica groups comprised of two months of observing the activities of the participants in group 1 which meets at the church hall. The practicing social actors are mostly women aged 50 and older, with chronic diseases and problems related to mental health. The women are from areas of high vulnerability of the town. Participation is voluntary by personal initiative.

The Unibiótica allows participants to access physical activities and advice on habits and lifestyles which are not available in their daily lives. It is a recognized practice amongst the population and health professionals as a marker (or good practice) to promote health in the location.

The analysis reveals the potential for Unibiótica in disciplining bodies by physical activity and positive expressions. Mechanisms such as the requirement of repetition of self-control and moderation are present as disciplinary techniques. Also highlighted are technologies of the self with specific rituals directed at the individual (morning fasting, drinking pure 
water, showering, sleeping on a hard bed with a wooden pillow) that place individuals in the process of self-transformation.

The analysis of this practice reveals its potential to stimulate the modelling of behavior through norms and prescriptions. There is an encouragement in the development of technologies for the self as a self-care and a self-creator of behaviour. The technologies or the government of the self are exercises, techniques, procedures aimed at a "certain number of operations upon one's own body and soul, thoughts, behaviors, or any form of being, thus obtaining self-transformation (...) not just in the obvious sense of acquiring certain skills, but also in the sense of acquiring certain attitudes" ${ }^{[22]}$. The fact that a big part of Unibiótica's public is consisted of women searching for groups with symptoms of depression, increases the evidence of their role as a device in which people transform the relationship with themselves.

It is also possible to identify the practice as an extension of biomedical normativity to be directed at the production of behaviour that incorporates the physical body and the deviations of normativity as an object to discipline and medicalize. It is important to highlight that the analysis of this practice reveals its potential of this practice in establishing a new modus vivendi: there are several autonomous personalities (to use a Foucauldian term) trying to build upon other logic in relation to self-care. Despite the component standardization being visible in this practice, which regulates and reproduces certain rules of conduct and reflex actions that change their way of being (the diet of the good life), it represents a possibility of overcoming the medication since it incorporates the value of diet, physical activity and mind and body care.

Another element that should be discussed is the autonomous characteristics of the non-institutionalized group, therefore encountering difficulties in "survival" and being accessible to an increased number of people. Thus accordingly, the practice remains a focal character, similar to other practices identified in the scenario.

\section{Criticism regarding medicalization in areas of everyday life}

In general, what is concluded in practices of health promotion in everyday life in the setting of the study is the low adherence to the offers available by the population. It is also evident that the main characteristic of the practices do not constitute as a systematic practice with follow-up mechanisms and evaluation enabling monitoring of the changes of habit within the targeted audience. Thus the practices contribute little to the creation of new habits even though they are able, to a greater or lesser degree, to provoke them. That's because no one sees synergy in the relationship between supply and demand coming from the practices of social and health needs, expressed by the population's views and values. It prevails a characteristic of consumption practices without advancing in the perspective of autonomous responsibility and solidarity in the sense that would represent each individual in creating their own path (or life project) according to one's own available possibilities regarding ways of life.

With this understanding, the study's findings allows to affirm that there is a "menu" of offers of health promotion practices in this scenario of the study that indicates a desirable reality, to contemplate different complementary aspects of health promotion, from those focused on modifying habits and lifestyles, to even those that prioritize components of structural changes and living conditions ${ }^{[19]}$. There are therefore several co-existent projects. However, most of these projects showed low capacity to mobilize resources on autonomy and personal responsibility.

It should be remembered that certain practices occur to materialize public policies, such as those that have been happening at the school. Then the degree of institutionalization and formalization is higher and would have been expected to have less capability of establishing autonomy and freedom. Other practices occur even without sustaining investment in public policy, such as Unibiótica. Would have been expected to have provided a greater capability in creating a new modus vivendi that exceed ways of reproducing models to maintain health. However, there is one contradiction: in practices where it is expected to have a greater area of freedom/autonomy by being deinstitutionalized, set up mechanisms of power movement patterns that reproduce standards and norms that cross social relationships. In these practices, stands out the defence of the body cult and overvaluing the technologies addressed to the self. The group Unibiótica is emblematic of this 
configuration of subjective modes, meaning that ways of defining the relationship of the subjects with themselves (mostly depressed women) in incorporating rules and regulations that must be put into practice.

One aspect to be considered in the analysis is that the practices shouldn't be interpreted as either good or bad, but in the gradation of its potential to be more or less autonouministic, reaffirming that the society is composed by uncountable organized practices of its normative institutions and many others, even though by not organizing a discourse (institutional, scientific) reveals certain areas, languages and meanings.

In general, what prevails is the focused practices about the risks or deviations from normality, contribute little to break up the social medicalization as it intensifies a model of negation of disease and pathology. Thus, there is the feedback of the biomedical paradigm now materialized in different practices and areas (in addition to traditional health services) which, combined with the fact of dealing with senses and meanings generated by people in relation to health and ways to having it, configure a new rationality. In this new rationality, the heterogeneity and conceptual imprecision mark the daily practice of health promotion from the more individualistic approaches to those most massifying.

\section{Conclusions}

It is concluded that health promotion in the social areas of the study setting presents itself in a more autonomistic manner whilst it organises itself by public or private initiatives whose ability to cope with the medicalization occurs in the expression of micro-interests, micro-identities in response to traditional institutionalised proposals. In these practices it would have been possible to state a more instituting style since in all the practices examined, there is a greater or lesser degree of elements that tend to be more autonomist and/or reinforce the medicalization by how social relationships are engendered and reflects the knowledge-power technologies. Thus, in all the practices examined, it is possible to realize an intention more or less regulatory with an outcome of a dynamic flow of relations between the different social actors. In this respect, the access to health promotion practices reveals disagreements between supply, demand and social needs.

Finally, if we consider the subtlety by which the mechanisms of social control and management of vulnerable populations and the technologies directed at the self, entering body and mind (such as invoking the positive behaviours of Unibiótica) or the ability to develop image-goals which reflect expected patterns of behaviour, values and habits (such as the full-time comprehensive school or the walk against dengue), furthermore the different times and parallel areas that the practices of health promotion materialized in the study setting, it can be affirmed that the health promotion is an organised discourse of life. This speech carries with it certain limits that allow the creation of solutions of continuity in daily practices creating opportunities so, autonomy is revealed in the configuration of new social relationships. These relationships are prohibited by vectors that intersect in the plans of the macro-and micro-social ways of life and put the promotion of health as a political reason. Above all, it is allowed to affirm that are various health promotions within the social areas of everyday life.

\section{References}

[1] Czeresnia D. O conceito de saúde e a diferença entre prevenção e promoção. In: Czeresnia D and Freitas CM Promoção da saúde: conceitos, reflexões, tendências. Rio de Janeiro: Editora Fiocruz. 2003: 39-54.

[2] Bacheladenski M and Matiello Jr E. Contributions from the critical leisure field to the health promotion. Ciência Saúde coletiva. 2010; 15(5): 2569-2579. PMid:20802889 http://dx.doi.org/10.1590/S1413-81232010000500031

[3] Mcqueen D. Foreword. In: Poland BD, Green LW and Rootman I. Settings for Health Promotion: linking theory and practice. London: Sage Publications, 2000.

[4] Dooris M. Healthy settings: challenges to generating evidence of effectiveness. Health Promotion International. 2005; 21(1): 55-65. PMid:16339774 http://dx.doi.org/10.1093/heapro/dai030

[5] Foucault M. A verdade e as Formas Jurídicas. Rio de Janeiro: Nau, 1996.

[6] Foucault M. Microfísica do poder. Rio de Janeiro: Graal, 2004.

Published by Sciedu Press 
[7] Foucault M. Em Defesa da Sociedade. São Paulo: Martins Fontes, 2005.

[8] Heller A. Sociologia de la vida cotidiana. Barcelona: Ediciones Península, 1977.

[9] Heller A. O cotidiano e a História. São Paulo: Ed. Paz e Terra, 2004.

[10] Minayo MCS. O desafio do conhecimento: pesquisa qualitativa em saúde. São Paulo: Hucitec, 2007.

[11] Minayo MCS. Hermenêutica-dialética como caminho do pensamento social. In: Minayo MCS, Deslandes SF. Caminhos do pensamento: epistemologia e método. Rio de Janeiro: Ed. Fiocruz. 2002: 83-107.

[12] Ferreira MS, Najar AL. Programas e campanhas de promoção da atividade física. Cienc Saúde Coletiva. 2005; 10: $207-219$. http://dx.doi.org/10.1590/S1413-81232005000500022

[13] Shah S, et al. A partnership for health - Working with schools to promote healthy lifestyle. Aust Fam Physician. 2011; 40(12): 1011-3. PMid:22146334

[14] Parcel GS, et al. The School as a setting for Health Promotion. In: Poland BD, Green LW and Rootman I. Settings for Health Promotion: linking theory and practice. London: Sage Publications. 2000: 86-137. http://dx.doi.org/10.4135/9781452232829.n3

[15] Veiga CG. A escolarização como projeto de civilização. Revista Brasileira de Educação. 2002; 21: 90-103.

[16] Carvalho MCB. A educação integral inscrita na política pública. 2007. Available from: http://www.cenpec.org.br/modules/biblioteca_digital/index.php?bib_10_id=5\&op=v_reg (accessed 28 December 2011).

[17] Valla VV. Educação, participação, urbanização: uma contribuição à análise histórica das propostas institucionais para as favelas do Rio de Janeiro, 1941-1980. Cadernos de Saúde Pública. 1985; 1(3): 282-296. http://dx.doi.org/10.1590/S0102-311X1985000300002

[18] Valadão MM. Saúde na Escola: um campo em busca de espaço na agenda intersetorial. Tese (Doutorado) - Faculdade de Saúde Pública, Universidade de São Paulo, São Paulo, 2004.

[19] Alvaro C, et al. Moving Canadian governmental policies beyond a focus on individual lifestyle: some insights from complexity and critical theories. Health Promotion International. 2011; 26(1): 91-9. PMid:20709791 http://dx.doi.org/10.1093/heapro/daq052

[20] Coelho DM, Fonseca TMG. As mil saúdes: para aquém e além da saúde vigente. Psicologia \& Sociedade. 2007; $19(2):$ 65-69. http://dx.doi.org/10.1590/S0102-71822007000200009

[21] Castro AL. Culto ao corpo e sociedade: mídia, estilos de vida e cultura de consumo. São Paulo: Annablume, 2003.

[22] Foucault M. Tecnologías del yo y otros textos afines. Barcelona: Paidós, 1990. 